\title{
DQPSK Directly Phase Modulated DFB for Flexible Coherent UDWDM-PONs
}

\author{
Iván N. Cano, Adolfo Lerín, and Josep Prat, Member, IEEE
}

\begin{abstract}
A bandwidth limited DFB laser directly phase modulated with a $5 \mathrm{~Gb} / \mathrm{s}$ DQPSK signal is demonstrated in a statistical UDWDM-PON. Optical DQPSK modulation was achieved by simply equalizing a 4-level waveform. An intradyne receiver based on a $120^{\circ}$ optical hybrid with straightforward differential decoding processing was used to detect and recover the data attaining a sensitivity of $-38 \mathrm{dBm}$ at $B E R=10^{-3}$. Negligible penalty was observed when adding a second user at $5 \mathrm{GHz}$ channel separation.

Index Terms - DFB, direct phase modulation, DQPSK, passive optical networks, UDWDM
\end{abstract}

\section{INTRODUCTION}

$\mathrm{A}$ FTER the decision of the full service access network (FSAN) committee for a time and wavelength division multiplexing (TWDM) as the second stage of the next generation passive optical networks (NG-PON2) standard, ultra-dense WDM (UDWDM) appears as a candidate for upcoming access network generations [1-3]. Though coherent UDWDM offers high sensitivity and coexistence with current PON deployments, the potential high cost and device complexity has limited its attractiveness to operators.

In order to simplify the transmitter (Tx), direct phase modulation has been proposed as an alternative. In [4], an optical differential phase shift keying (DPSK) modulation of a distributed feedback (DFB) laser was reported with direct detection. Similarly, in [5] a direct phase modulated DFB with DPSK data was proposed for optical network unit (ONU) Tx and detected with a heterodyne receiver (Rx).

Service providers are also interested in offering diverse services to heterogeneous users with different bit rates within the access networks [2, 6]. The terminals, however, are geographically spread from the central office causing dissimilar power budgets. In addition, the bandwidth (BW) could be allocated dynamically depending on the individual needs in time and available spectrum. To further increase the flexibility of the network, advanced modulation formats have to be adopted [3]. Some experiments with multilevel signal generation without optical modulators have been published. In [7] a chirp-managed distributed-Bragg-reflector (DBR) was

Manuscript received July 17, 2015. This work was supported in part by the European FP7 project COCONUT (G.A. 318515) and the Spanish Ministry of Science and Innovation under grant TEC2011-25215 (ROMULA).

The authors are with Universitat Politecnica de Catalunya (UPC), Jordi Girona 1-3, E-08034, Barcelona, Spain (e-mail: ivan.cano@ tsc.upc.edu). proposed, whereas in [8] optical injection locking was used. However, the first solution required an optical spectrum reshaper filter and the second, a master and slave lasers, turning complex the Tx and its application for an ONU.

In this paper we report a directly phase modulated DFB with differential quadrature phase shift keying (DQPSK). The technique maps a four-level signal into $90^{\circ}$ difference phases and is proposed as a cost-efficient Tx for ONUs. Experimental results at $2.5 \mathrm{~Gb} / \mathrm{s}$ and $5 \mathrm{~Gb} / \mathrm{s}$ are presented with a $2 \mathrm{GHz}$ limited BW DFB and an intradyne Rx based on a $120^{\circ}$ hybrid. The system hardware is identical to that of DPSK with the exception of the differential coder and modulation mapping. Since these functions can be potentially configured digitally by software, the modulation format can be adapted during the registration process or layer 2 protocols according to the user bit rate requirement, power budget and available spectrum for flexible BW allocation.

\section{EXPERIMENTAL SETUP}

Fig. 1 depicts a diagram of the experimental setup. In order to simplify the systems, we used different wavelengths for upstream and downstream. Two independent sequences of $2^{18}$ bits each were the inputs of a DQPSK coder. The codified bits were then mapped to a four-level signal. DPSK data were also generated by differentially codifying one of the bit strings. A separate symbol stream was also generated for a second user. The signals were uploaded to the two channels of an arbitrary waveform generator (AWG) and electrically amplified. Then they directly modulate two equalized DFB lasers $\left(\lambda_{1}=1549.3 \mathrm{~nm}\right.$ and $\left.\lambda_{2}=1549.4 \mathrm{~nm}\right)$. The high pass equalization (based on an RC network), in the DFBs converted the adiabatic frequency modulation into phase modulation [5]. The result was a signal with either $0^{\circ}$ and $180^{\circ}$ variations (DPSK) or $0^{\circ}, 90^{\circ}, 180^{\circ}, 270^{\circ}$ phases (DQPSK). The ONUs had DFB lasers with $4 \mathrm{MHz}$ linewidth whose wavelength was tuned through temperature for flexible grid operation [1]. The optical signals from the ONUs were joined with a $3 \mathrm{~dB}$ coupler and sent through single mode fiber (SMF) with $0 \mathrm{dBm}$ total launched power. At the end of the link a variable optical attenuator (VOA) adjusted the received power.

The optical line terminal (OLT) Rx consisted of a $3 \times 3120^{\circ}$ optical coupler which mixed the optical data signal with a local oscillator (LO) emitting at the same wavelength as the Tx laser of $\mathrm{ONU}_{1}\left(\lambda_{1}\right)$. We used as $\mathrm{LO}$ an external cavity laser (ECL) with $100 \mathrm{kHz}$ linewidth mainly to avoid strong 


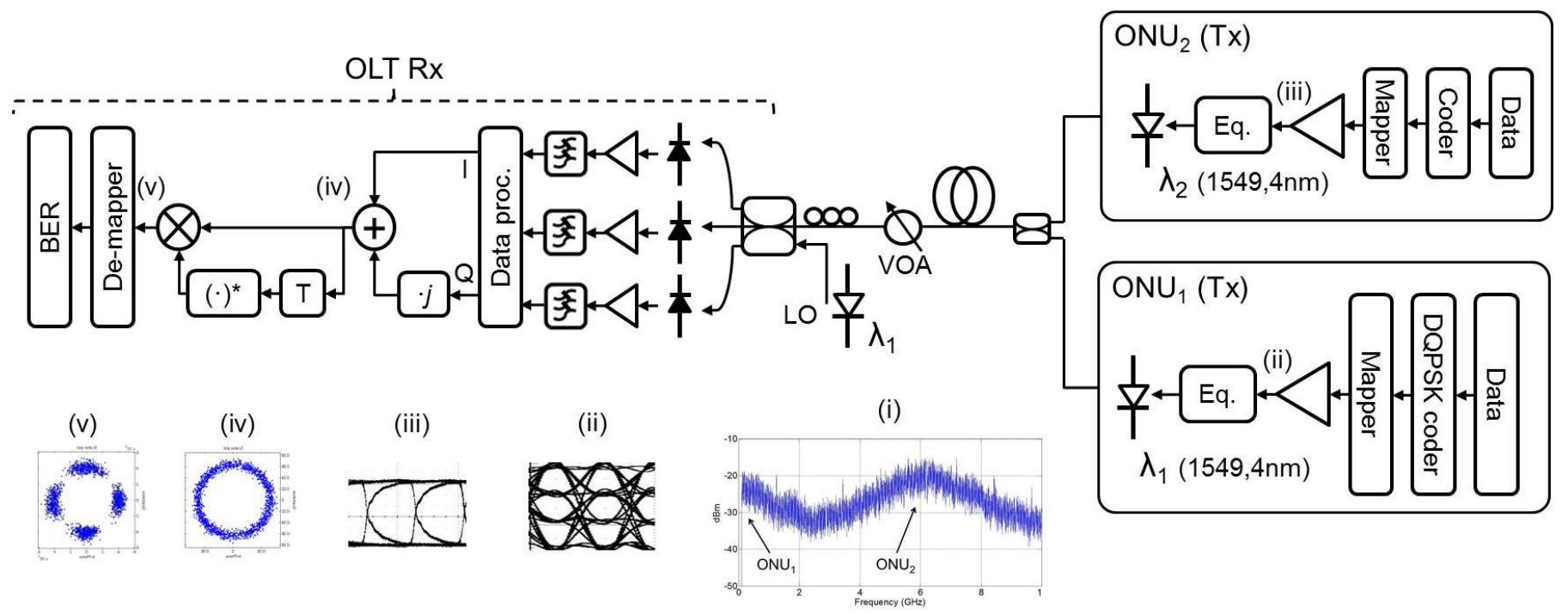

Fig. 1. Experimental setup schematics; (i) electrical spectrum of the Rx signal comprising the two ONUs with the LO emitting at $\lambda_{1}$, (ii) eye diagram of the 4level mapped Tx signal for DQPSK, (iii) eye diagram of the 2-level mapped Tx signal for DPSK (iv) constellation of the Rx signal from ONU 1 before decodification, (v) $\mathrm{ONU}_{1} \mathrm{Rx}$ decodified constellation for DQPSK.

variations in the wavelength but also to keep the total linewidth close to $4 \mathrm{MHz}$. The output power of the $\mathrm{LO}$ was set at its maximum of $0.5 \mathrm{dBm}$. A polarization controller (PC) was used to compensate the fluctuations of the state of polarization (SOP) produced in the fiber. Polarization independency can be obtained with a simple technique like the one demonstrated in [9]. The three outputs of the optical coupler were detected with $10 \mathrm{GHz}$ photodiodes (PD) followed by low-noise electrical amplifiers. A 50 GSa realtime oscilloscope then sampled and processed the electrical signals computing the in-phase (I) and quadrature (Q) components following the equations of [10]. The obtained complex samples were multiplied with the complex conjugate of the previous symbol for differential decoding. Afterwards, they passed through a 4th order low-pass filter (LPF) with cutoff frequency at $90 \%$ of the signal BW. The symbols were then de-mapped and the bit error rate (BER) was computed. It is important to highlight that the same Rx was employed for both DPSK and DQPSK.

\section{RESULTS}

Firstly, the system was tested in back-to-back (btb) with DQPSK at $2.5 \mathrm{~Gb} / \mathrm{s}$. Initially, the channel spacing between ONUs in upstream was set at $12.5 \mathrm{GHz}$. The Tx electrical signal amplitude was tuned to get the desired phase changes and diminish the residual amplitude modulation $\left(\mathrm{AM}_{\mathrm{res}}\right)$ as in [5]. The results of BER against the OLT Rx optical input power are plotted in Fig. 2. At a pre forward error correction (FEC) limit of BER $=10^{-3}$, the measured Rx sensitivity with DQPSK was approximately $-41 \mathrm{dBm}$. Although the signal was detected properly, there was a BER floor approaching $\mathrm{BER}=2 \cdot 10^{-4}$. There were two causes for this effect: the $\mathrm{AM}_{\text {res }}$ added to the detected signal and the phase noise which was not fully compensated as can be seen in the constellation inset of Fig. 2.
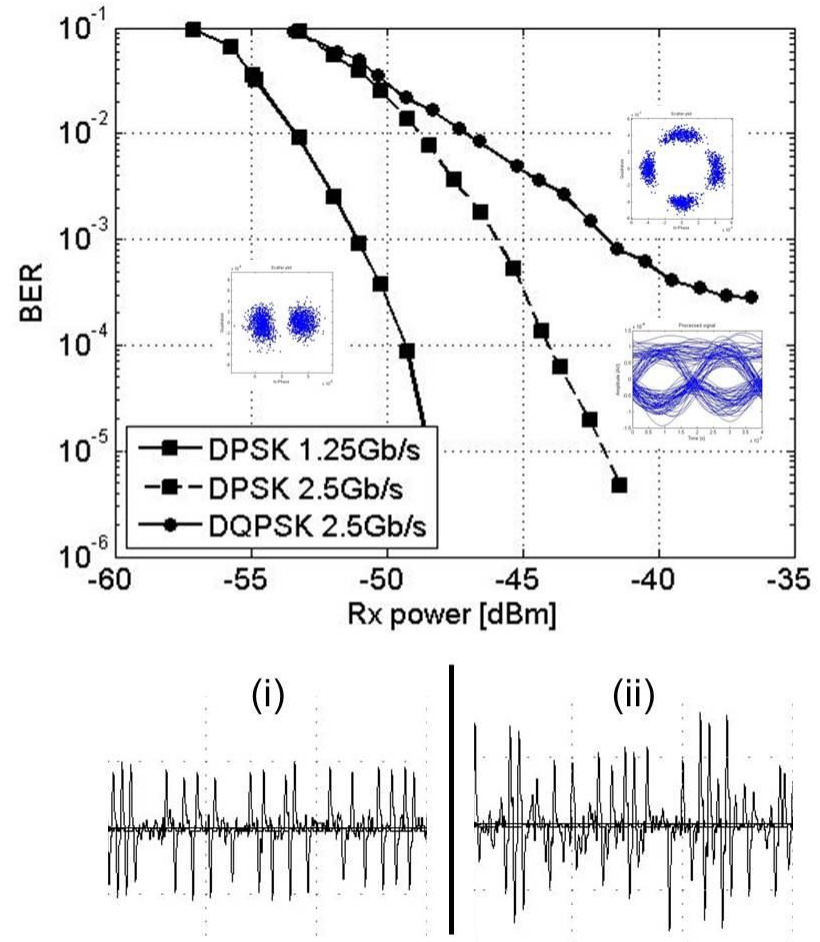

Fig. 2. BER against Rx power for DPSK $(1.25 \mathrm{~Gb} / \mathrm{s}, 2.5 \mathrm{~Gb} / \mathrm{s})$ and DQPSK (2.5Gb/s) signals. The insets show the $\mathrm{AM}_{\text {res }}$ for (i) $1.25 \mathrm{~Gb} / \mathrm{s}$ DPSK, and (ii) $2.5 \mathrm{~Gb} / \mathrm{s}$ DQPSK.

For comparison, the graphs of DPSK signal transmission are also included in Fig. 2. At BER $=10^{-3}$ the Rx sensitivities were $-51 \mathrm{dBm}$ and $-46 \mathrm{dBm}$ for $1.25 \mathrm{~Gb} / \mathrm{s}$ and $2.5 \mathrm{~Gb} / \mathrm{s}$ DPSK respectively. At the same symbol rate, with negligible phase noise the power penalty should be limited to $3 \mathrm{~dB}$ [11]. In our case, however, no phase estimation was carried out and hence, phase noise limited the performance of DQPSK since its tolerance to such impairment is about six times less than for DPSK [12]. As a result, the laser linewidth requirements are 
more stringent for DQPSK. In addition, the amplitude of the four-level modulating signal for DQPSK was 1.5 times higher than the binary one for DPSK to achieve the proper phase shifts as observed in insets (i)-(ii) of Fig. 1. The result was that the peak-to-peak voltage $\left(\mathrm{V}_{\mathrm{p}-\mathrm{p}}\right)$ of the $\mathrm{AM}_{\text {res }}$ generated by direct modulating the DFB was stronger for DPQSK $\left(\mathrm{V}_{\mathrm{p}-}\right.$ $\mathrm{p}=32.2 \mathrm{mV})$ than DPSK $\left(\mathrm{V}_{\mathrm{p}-\mathrm{p}}=21.04 \mathrm{~mW}\right)$, and consequently, increased the noise in the Rx DQPSK signal (insets in fig. 2). External modulation with a dual mach-zehnder modulator (MZM) would diminish the $\mathrm{AM}_{\mathrm{res}}$ and improve the performance by at least $2 \mathrm{~dB}$ as with DPSK format [5].

$\mathrm{ONU}_{2}$ laser wavelength was then tuned for evaluating the minimal spectral separation needed. Both ONUs operated at $2.5 \mathrm{~Gb} / \mathrm{s}$. The LO in OLT Rx was adjusted to detect $\mathrm{ONU}_{1}\left(\lambda_{1}\right)$ which was fixed and the effect of neighbor channels (lower and upper) was measured at a constant Rx optical power of -39 $\mathrm{dBm}$. We varied $\lambda_{2}$ from $\lambda_{1}-0.08 \mathrm{~nm}$ to $\lambda_{1}+0.08 \mathrm{~nm}$ by thermal tuning. The BER against the channel separation is plotted in Fig. 3 for both modulation formats. For DQPSK, the minimum frequency spacing to keep the penalty $<1 \mathrm{~dB}$ was as low as 5 GHz. On the other hand, for the same bit rate, with DPSK modulation a spectral separation of $8.75 \mathrm{GHz}$ was needed. Although the spectral efficiency was enough for our experiment, it could be enhanced by employing pulse shaping techniques [2].

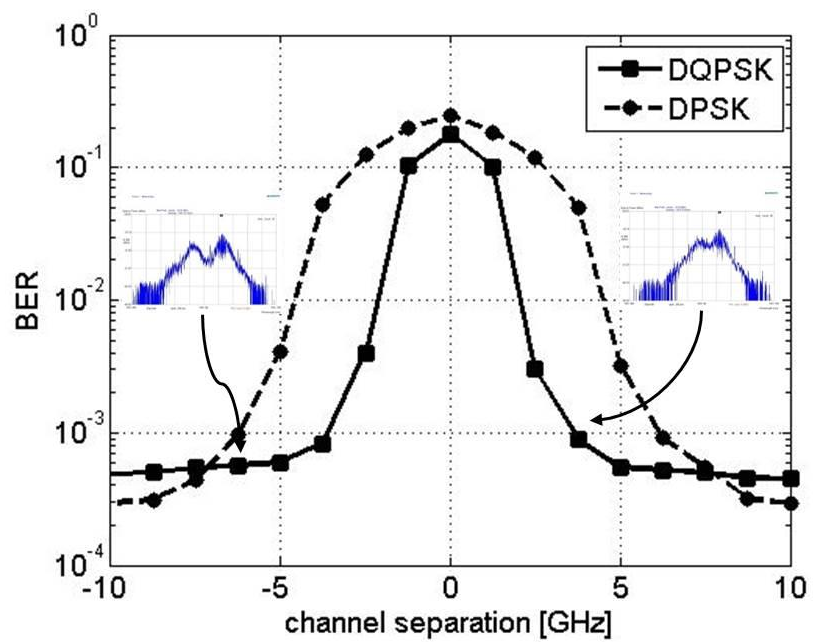

Fig. 3. BER against channel separation for $1.25 \mathrm{~Gb} / \mathrm{s}$ DPSK and $2.5 \mathrm{~Gb} / \mathrm{s}$ DQPSK modulated signals. The insets show the optical spectrum transmitted in the fiber link.

Having verified the proper detection of the signals, the system was tested with a fiber link as long as $100 \mathrm{~km}$. Both ONUs were modulated with $2.5 \mathrm{~Gb} / \mathrm{s}$ DQPSK data and their output power was limited to $0 \mathrm{dBm}$. The channel spacing was set to $6.25 \mathrm{GHz}$. The BER against the OLT Rx optical power of $\mathrm{ONU}_{1}$ is presented in Fig. 4. For this measurement, only the central sample was considered for symbol decision after data processing. At $\mathrm{BER}=10^{-3}$ the Rx sensitivity in btb was of -41 $\mathrm{dBm}$, identical to the value obtained with $12.5 \mathrm{GHz}$ spectral separation. The power penalties for fiber lengths of $50 \mathrm{~km}, 75$ $\mathrm{km}$, and $100 \mathrm{~km}$ with respect to btb were $1.3 \mathrm{~dB}, 1.5 \mathrm{~dB}$, and 2 $\mathrm{dB}$ respectively. There were two effects that caused these penalties. First, the polarization was not totally controlled and required continuous adjustment. Second, the emission frequency of the DFB and LO lasers was fluctuating around $\pm 100 \mathrm{MHz}$. The electrical signal modulating the DFB needed high power to produce the required phase shifts. This produced instantaneous changes in the temperature of the laser which caused wavelength drifts [13]. Since there was no frequency offset estimation these drifts produced around $1 \mathrm{~dB}$ penalty [14]. Non-linear and dispersive effects were negligible in this experiment.

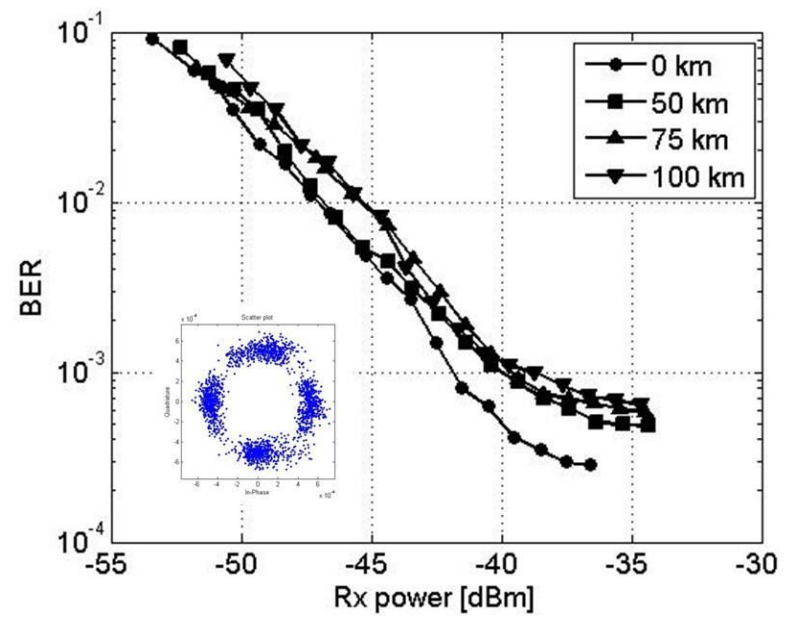

Fig. 4. BER against Rx power of $2.5 \mathrm{~Gb} / \mathrm{s}$ DQPSK signal with several fiber lengths.

At $100 \mathrm{~km}$ fiber distance, the Rx sensitivity for $\mathrm{BER}=10^{-3}$ was $-39 \mathrm{dBm}$ with $2.5 \mathrm{~Gb} / \mathrm{s}$ DQPSK modulation data. The launched power was $0 \mathrm{dBm}$, hence the loss budget was $39 \mathrm{~dB}$. Considering a fiber attenuation of $0.25 \mathrm{~dB} / \mathrm{km}$ and a power splitter based network, the PON could serve 16 users over 100 $\mathrm{km}$ fiber link.

Since the DPSK signal could be detected suitably at 2.5 $\mathrm{Gb} / \mathrm{s}$ (Fig. 2), we also tested the DQPSK transmission at that symbol rate, i.e. bit rate of $5 \mathrm{~Gb} / \mathrm{s}$. In order to avoid channel interference, we doubled the spectral separation between ONUs to $12.5 \mathrm{GHz}$. We simply inferred this value from the results of fig. 3. The BER against the OLT Rx power for 5 $\mathrm{Gb} / \mathrm{s}$ DQPSK is shown in Fig. 5 with several fiber lengths. In this case, we considered three samples for symbol decision. This was the reason for the slightly lower BER floor appearing in Fig. 5 compared with Fig. 4.

The measured Rx sensitivity at $\mathrm{BER}=10^{-3}$ was $-38 \mathrm{dBm}$ in btb. Remarkably, this value was just $3 \mathrm{~dB}$ worse than the 2.5 $\mathrm{Gb} / \mathrm{s}$ signal in btb. The penalty when transmitting through 50 $\mathrm{km}, 75 \mathrm{~km}$, and $100 \mathrm{~km}$ of fiber was $1.2 \mathrm{~dB}, 1.8 \mathrm{~dB}$, and 2.4 $\mathrm{dB}$ respectively. These values were similar to those previously obtained with $2.5 \mathrm{~Gb} / \mathrm{s}$ DQPSK. For $100 \mathrm{~km}$ fiber link at $\mathrm{BER}=10^{-3}$ the loss budget was $36 \mathrm{~dB}$ with launched power of 0 $\mathrm{dBm}$. Hence, considering the same fiber loss as before, with 5 $\mathrm{Gb} / \mathrm{s}$ DQPSK modulation, the PON could provide service to 8 users in a $100 \mathrm{~km}$ fiber link.

For comparison, a single channel with $5 \mathrm{~Gb} / \mathrm{s}$ DPSK data at btb was also measured. The performance of the DSPK signal was limited due to the restrained BW of the DFB laser, closing 
the eye diagram in the Rx. As seen in Fig. 5, the BER was above the FEC threshold and presented a floor around $2 \cdot 10^{-2}$. Thus, if a user requests a bit rate of $5 \mathrm{~Gb} / \mathrm{s}$ and complies as within the loss budget margin, then it could transmit with DQPSK. The pre-coder and demapping should be updated, which could be potentially done by software through layer- 2 protocols or during the registration process.

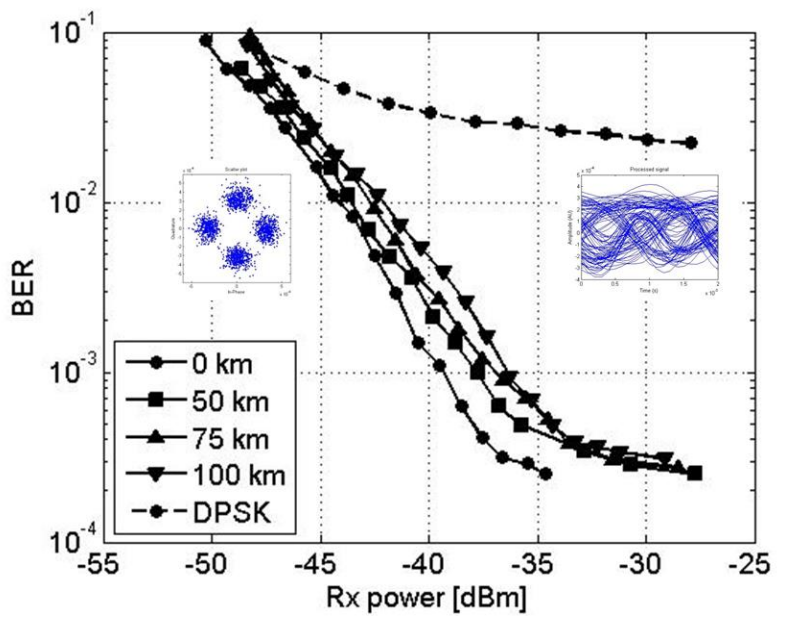

Fig. 5. BER against Rx power of DQPSK signal with several fiber lengths at a bit rate of $5 \mathrm{~Gb} / \mathrm{s}$. The dotted curve and eye-diagram corresponds to $5 \mathrm{~Gb} / \mathrm{s}$ DPSK.

Finally, a phase estimation stage based on Viterbi-Viterbi algorithm was tested [15]. The phase estimate was computed by averaging 5 samples, unwrapped and then it was subtracted from the measured phase. As observed in Fig. 6, the phase compensation was effective and removed most of the accumulated phase noise producing a clearer constellation. The performance was thus improved reaching BER values below the floor that appeared in previous measurements. This phase compensation stage could lower the laser linewidth requirement; however, it adds complexity and thus increases the cost of the Rx.

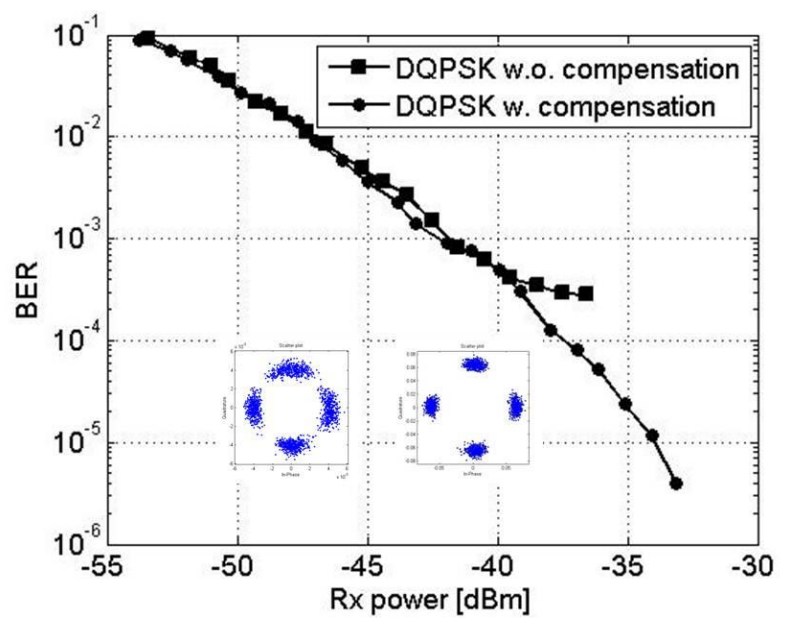

Fig. 6. BER against Rx power of DQPSK signal with and without phase compensation stage. The constellation diagrams correspond to Rx power of $36 \mathrm{dBm}$ with (right) and without (left) phase compensation.

\section{CONCLUSIONS}

The first DQPSK direct phase modulated DFB laser was demonstrated. The signal was properly detected by means of a $120^{\circ}$ hybrid based coherent Rx. Bit rates of $1.25 \mathrm{Gbaud} / \mathrm{s}$ and $2.5 \mathrm{Gbaud} / \mathrm{s}$ were measured with Rx sensitivities of $-41 \mathrm{dBm}$ and $-38 \mathrm{dBm}$ and channel separation of $6.25 \mathrm{GHz}$ and 12.5 $\mathrm{GHz}$ respectively. The system was tested with fiber lengths of up to $100 \mathrm{~km}$ and a maximum penalty of $3 \mathrm{~dB}$ penalty was noticed compared with btb. With DQPSK we were able to transmit at $5 \mathrm{~Gb} / \mathrm{s}$ which was not possible with DPSK due to the laser BW. As the OLT Rx front-end was identical to the DPSK case, the modulation format can potentially be selected through software depending on the user needs in an UDWDM PON.

\section{REFERENCES}

[1] J. Prat, M. Angelou, C. Kazmierski, R. Pous, M. Presi, A. Rafel, G. Vall-1losera, I. Tomkos, E. Ciaramella, "Towards ultra-dense wavelength-to-the-user: the approach of the COCONUT project," in Proc. ICTON, Cartagena, Spain, June 23-27, 2013, paper Tu.C3.2.

[2] A. Shahpari, R. Ferreira, V. Ribeiro, A. Sousa, S. Ziaie, A. Tavares, Z. Vujicic, F. P. Guiomar, J. D. Reis, A. N. Pinto, A. Teixeira, "Coherent ultra dense wavelength division multiplexing passive optical networks," Opt. Fiber Technol., (2015, July 15) doi:10.1016/j.yofte.2015.07.001. Available: http://dx.doi.org/10.1016/j.yofte.2015.07.001.

[3] A. Teixeira, A. Shahpari, J. D. Reis, R. Ferreira, "Flexible access networks," in Proc. ICTON, Graz, Austria, July 6-10, 2014, paper Tu.B3.1.

[4] R. S. Vodhanel, "5 Gbit/s direct optical DPSK modulation of a 1530-nm DFB laser," IEEE Photon. Technol. Lett., vol. 1, pp. 218-219, Aug. 1989.

[5] I. N. Cano, A. Lerín, V. Polo, and J. Prat, "Direct phase modulation DFBs for cost-effective ONU transmitter in udWDM PONs," IEEE Photon. Technol. Lett., vol. 26, pp. 973-975, May 2014.

[6] V. Ataie, E: Temprana, L. Liu, Y. Myslivets, P. P. Kuo, N. Alic, S. Radic, "Flex-grid compatible ultra-wide frequency comb source for $31.8 \mathrm{~Tb} / \mathrm{s}$ coherent transmission of 1520 UDWDM channels," in Proc. OFC,San Francisco, CA, Mar. 11-13, 2014, paper Th5B.7.

[7] W. Jia, Y. Matsui, D. Mahgerefteh, I. Lyubomirsky, C-K Chan, "Generation and transmission of 10-Gbaud optical 3/4-RZ-DQPSK signals using a chirp-managed DBR laser," IEEE J. Lightw. Technol., vol. 30, pp. 3299-3305, Nov. 2012.

[8] Z. Liu, J. Kakande, B. Kelly, J. O'Carroll, R. Phelan, D. J. Richardson, R. Slavík, "Modulator-free quadrature amplitude modulation signal synthesis," Nat. Commun.,5:5911, doi: 10.1038/ncomms 6911, Dec. 2014.

[9] I. N. Cano, A. Lerín, V. Polo, J. Prat, "Simplified polarization diversity heterodyne receiver for $1.25 \mathrm{~Gb} / \mathrm{s}$ cost-effective udWDM-PON ," in Proc OFC, San Francisco, CA, Mar. 11-13, 2014, paper W4G.2.

[10] C. Xie, P. Winzer, G. Raybon, A. H. Gnauck, B. Zhu, T. Geisler, B. Edvold, "Colorless coherent receiver using $3 \times 3$ coupler hybrids and single-ended detection," Op. Express 20, pp. 1164-1171, Jan 2012.

[11] K. Kikuchi, "Coherent optical communication systems," in Optical fiber telecommunications, I. P. Kaminow, T. Li, A. E: Willner, Ed., New York: Elsevier, 2008, pp. 95-129.

[12] A. H. Gnauck, P. J. Winzer, "Optical phase-shift-keyed transmission," IEEE J. Lightw. Technol., vol. 23, pp. 115-130, Jan. 2005.

[13] V. Polo, P. Borotau, A. Lerín, J. Prat, "DFB laser reallocation by thermal wavelength control for statistical udWDM in PONs," in Proc. of ECOC, Cannes, France, Sept.21-25, 2014, paper P.4.13.

[14] J. Tabares, V. Polo, I. Cano, J. Prat, "Automatic $\lambda$-control with offset compensation in DFB intradyne receiver for udWDM-PON," IEEE Photon. Technol. Lett., vol. 27, pp. 443-446, Feb. 2015.

[15] S. J. Savory, "Digital coherent optical receivers: algorithms and subsystems," IEEE J. Sel. Topics. Quantum Electron. , vol. 16, pp. 1164-111179, Sept. 2010. 